\title{
Stolz, Glück, Unvernunft
}

Liebe Leserinnen, liebe Leser,

Stolz, superbia, hat in der Geschichte überwiegend keinen guten Ruf. Die Römer mochten ihren letzten König, Tarquinius Superbus, so wenig, dass sie ihn verjagten; es hätte ihnen also fern gelegen, ihm einen positiven Beinamen zu geben. Nach der Lehre der katholischen Kirche ist Stolz das erste der sieben Hauptlaster., Stolz" ist also ein moralischer Begriff. Zur Schau getragener Stolz fällt auf und wird verpönt, vor allem, wenn er sich auf etwas als negativ Eingeschätztes richtet. Stolz, sagt die Lehrmeinung, entfremdet den Stolzen Gott und den Mitmenschen; er bringt inn auf die fatale Bahn. Die Moral hat etwas gegen den Stolz; sie gesteht dem Menschen bestenfalls den Stolz auf eine Gott wohlgefällige oder der Menschheit dienliche Leistung zu.

Bezüglich meiner hier beabsichtigten Ausführungen meine ich aber nicht das christliche Hauptlaster, auch nicht den unberechtigten oder gar neurotischen Stolz. Ich meine hier - auf der psychologischen Ebene, also weit unter der moralischen das Grundgefühl von Stolz oder Scham. Es tritt spontan auf und sucht sich einen Inhalt, oder wird von einem Inhalt stimuliert. Nichts hindert es dabei daran, sich auch einem unmoralischen Inhalt zuzuwenden. Als Gefühl wird es dem Menschen in der Regel nicht einmal bewusst, jedoch beeinflusst es seine Entscheidungen. Es ist unkontrollierbar und viel naturhafter als der moralisch bewertete Stolz.

Weiterhin glaube ich auch nicht, dass es unmittelbar die eigene Leistung ist, der das Grundgefühl des Stolzes gilt. Im Gegenteil: Ist doch der Mensch stolz auf das, was inm unverdient zufällt. Ist er edel von Geburt, wird ihm darauf mehr Stolz zugebilligt, als wenn er als Parvenü seine gesellschaftliche Stellung durch eigene Leistung erreicht hat. Umgekehrt schämt er sich für ein von Geburt auf entstelltes Gesicht, wogegen er auf Narben, die er sich durch einen Sportunfall oder eine studentische Mensur zugezogen hat, eher stolz ist. Ich halte sogar dafür: Erklärt er sich als stolz auf die eigene Leistung, dann meint er eigentlich seine erwiesene - letztlich nicht erworbene - Befähigung dazu, nicht aber die aufgewandte Mühe; im Gefühl des Stolzes spielt er letztere eher herunter. So ist der Mensch - je nach Temperament - stolz auf sein Glück und schämt sich für sein Unglück. In diesem Sinne sind Stolz und Scham amoralisch, wie etwa Lachen und Weinen.

Damit erkläre ich mir auch die allfällig auftretende Unvernunft. Wo immer der Mensch eine ausreichende Chance erspürt, will er sein Glück probieren, zumeist ohne sich darüber bewusst Rechenschaft zu geben. Das fällt ihm viel leichter und reizt ihn mehr, als statt dessen einem Unglück vorzubeugen. So schlägt er etwa im Internet angebotene Sicherungsmaßnahmen leichtsinnig aus, beachtet nicht Gefährdungshinweise, nimmt Geschäftsbedingungen der Anbieter nicht konsequent zur Kenntnis, erteilt ungeprüft Genehmigungen zur Datenweitergabe, und so fort. Das tut er nicht allein, weil ihm Maßnahmen Mühe bereiten, Zeit und Geld kosten, sondern auch weil ihm Glückvertrauen und Zuversicht letztlich näher liegen. Das führt ihn zu der erwähnten Unvernunft, obwohl Lehrmeinungen und eigene Erfahrungen gegen das Glückvertrauen sprechen.

Die Gesellschaft, die überwiegend aus solchen Leichtsinnigen besteht, hat aber Verständnis dafür. Sie rechnet sogar damit. Ich meine: Ohne den Leichtsinn seiner Kunden liefe das Internet nicht rund. Und ich glaube, liebe Leserinnen und Leser, daran wird sich nicht viel ändern. Wie kann der Mensch bei all dem Neuen, das ihm zustößt, anders als auf sein Glück zu vertrauen? Kennt er doch selbst die unmittelbare Zukunft nicht. So macht ihn das Glück, wenn es eintrifft, stolz, insbesondere, wenn es ihm ohne Mühe und unverdient zufällt. Dieser Stolz ist kein christliches Hauptlaster, sondern ein unvermeidliches Grundgefühl. Unwillkürlich umarmt der Mensch mit ihm das unverdiente Glück.

Mit freundlichen Grüßen, Ihr

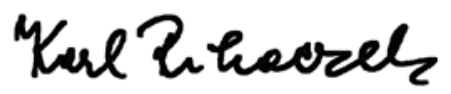

